\title{
"Você viu o corpo?" - A saúde pública no Brasil em uma perspectiva crítica e interpretativa comparada, da gripe espanhola à pandemia da Covid-19
}

"Did you see the body?" - Public health in Brazil in a critical and interpretive comparative perspective, from the Spanish flu to the Covid-19 pandemic

"¿Viste el cuerpo?" - La salud pública en Brasil en una perspectiva comparativa crítica e interpretativa, de la gripe española a la pandemia de Covid-19

\section{Resumo}

O objetivo do estudo foi comparar, por meio da análise crítica e interpretativa, o passado da crise epidêmica da gripe espanhola e o presente da crise pandêmica da Covid-19 no Brasil. Para efeito, aplicou-se o método científico dialético através de uma revisão integrativa da literatura, examinando-se dados coletados das bases do Google Scholar, PubMed e Lilacs. Como resultados, observou-se que a disseminação das doenças em ambas as pandemias estudadas, decorreu devido ao negacionismo social e governamental que favoreceu a falta de medidas de contenção e, consequentemente a sobrecarga de sistemas, refletindo sobre o número de casos da doença que causaram diversas mortes em grande nível, ambas refletiram em consequências em comunidades com pouca infraestrutura e falta de acesso ao saneamento urbano inadequado, tanto em uma quanto a outra existiu o uso de máscaras, o lavar das mãos e também o distanciamento social, assim como a grande quantidade de notícias falsas espalhadas pela comunidade. Conclui-se que há semelhanças entre o passado e o presente no que se refere as causas e consequências das pandemias, sendo importante analisar e comparar os fatores e concepções históricas, sociais e econômicas presente nas várias conjunturas da saúde populacional.

Palavras-chave: Sars-Cov-2; Vírus; Saneamento básico; Influenza pandêmica, 1918-1919; Sistemas de saúde.

\begin{abstract}
The aim of the study was to compare, through critical and interpretive analysis, the past of the Spanish flu epidemic crisis and the present of the Covid-19 pandemic crisis in Brazil. For this purpose, the dialectical scientific method was applied through an integrative literature review, examining data collected from Google Scholar, PubMed and Lilacs databases. As a result, it was observed that the spread of diseases in both pandemics studied was due to social and governmental denialism that favored the lack of containment measures and, consequently, the overload of systems, reflecting on the number of cases of the disease that caused several deaths at a high level, both reflected in consequences in communities with little infrastructure and lack of access to inadequate urban sanitation, in both there was the use of masks, washing of hands and also social distancing, as well as the great amount of fake news spread by the community. It is concluded that there are similarities between the past and the present regarding the causes and consequences of pandemics, and it is important to analyze and compare the factors and historical, social and economic concepts present in the various conjunctures of population health.
\end{abstract}

Keywords: SARS-CoV-2; Virus; Basic sanitation; Influenza pandemic, 1918-1919; Health systems. 


\begin{abstract}
Resumen
El objetivo del estudio fue comparar, a través del análisis crítico e interpretativo, el pasado de la crisis de la epidemia de gripe española y el presente de la crisis de la pandemia de Covid-19 en Brasil. Para ello, se aplicó el método científico dialéctico a través de una revisión integrativa de la literatura, examinando datos recopilados de las bases de datos Google Scholar, PubMed y Lilacs. Como resultado, se observó que la propagación de enfermedades en ambas pandemias estudiadas se debió al negacionismo social y gubernamental que favoreció la falta de medidas de contención y, en consecuencia, la sobrecarga de los sistemas, repercutiendo en el número de casos de la enfermedad que provocó varias muertes a un alto nivel, ambas reflejadas en consecuencias en comunidades con poca infraestructura y falta de acceso a saneamiento urbano inadecuado, en ambas hubo uso de mascarillas, lavado de manos y también distanciamiento social, así como la gran cantidad de falsos noticias difundidas por la comunidad. Se concluye que existen similitudes entre el pasado y el presente en cuanto a las causas y consecuencias de las pandemias, siendo importante analizar y comparar los factores y conceptos históricos, sociales y económicos presentes en las diversas coyunturas de salud de la población.
\end{abstract}

Palabras clave: SARS-CoV-2; Virus; Saneamiento; Influenza pandémica, 1918-1919; Sistemas de salud.

\title{
1. Introdução
}

As pandemias, as epidemias e as endemias evidenciam e intensificam as fragilidades e desigualdades no mundo, provocando incertezas. No final do ano de 2019, a Organização Mundial de Saúde (OMS) anunciou que a infecção, denominada Coronavírus Disease 2019 (Covid-19), ocasionada pelo vírus da Síndrome Respiratória Aguda Grave do Coronavírus 2 (Sars-Cov-2) era uma emergência global de saúde, classificando a patologia como pandemia (Santos, 2020; Arias; 2020; Segata, 2020).

O primeiro local de transmissão da doença e contaminação foi na cidade Wuhan, na China, que passou a ser definida como o epicentro da patologia. Logo, a disseminação começou a ocorrer entre os países, atravessando diversos continentes, prosseguindo para o Brasil por meio de viagens aéreas. Enquanto que nos diversos países as autoridades promoveram medidas de contenção e prevenção da doença, no Brasil os primeiros casos suspeitos da Covid-19 eram dispensados pelo Governo. Este cenário provocado pela doença não é recente, já que ocorreram graves epidemias desde o século XIX, que torna aparente crises e fragilidades nos sistemas de saúde, acometendo diretamente os mais pobres (Santos, 2020; Arias; 2020; Tesini, 2021; Cardoso et al., 2020; Aquino et al., 2020).

Anteriormente à pandemia da Covid-19, ocorreu a pandemia da gripe espanhola no período da primeira guerra mundial no ano de 1918, ocasionado pelo vírus incomum da Influenza A, do subtipo H1N1. Sua origem é controversa, porém, os soldados americanos que viajaram para a França para lutar durante a guerra foram apontados como os causadores da disseminação da doença na Europa. A doença se alastrou por todos os continentes em um pequeno intervalo de tempo, acometendo diversas pessoas, recebendo denominação pelas mídias como uma "gripe democrática", uma vez que atingiu até as figuras mais importantes da sociedade, independente da classe social, como o Presidente da República Rodrigues Alves (Junior et al., 2018; Goulart, 2005; Hochman, 1993).

Entretanto, essa definição se torna contraditória aos estudos realizados, nos quais mostram que as doenças transmissíveis sempre alcançam a população de forma heterogênea, prejudicando os mais pobres em um primeiro momento (Campelo et al., 2014; Garcia et al., 2016; Santos, 2021; Andrade et al., 2015). Inúmeras informações relacionadas à epidemia da gripe espanhola foram acobertadas, já que era possível que outras tropas pudessem usá-las contra os inimigos (Barry, 2005; Ujvari, 2009). Por consequência, foi criado na população um sentimento de desinformação, pois não houve conhecimento sobre o que estava acontecendo no momento e, consequentemente, a população foi contra todas as medidas de prevenção que estavam por vir (por exemplo, o uso da vacina). Portanto, pode-se entender que a informação é uma chave da ciência (Abreu, 2020; Goulart, 2005).

Ambas as doenças supracitadas são definições de processos históricos que estarão sempre marcados na memória dos indivíduos que sofreram e passaram por estas moléstias. Embora a pandemia da covid-19 ainda esteja ocorrendo, é possível 
identificar diversas semelhanças comparativas entre as duas pandemias, além dos sintomas parecidos (falta de ar, febre, entre outros) por afetarem o sistema respiratório. Isto é, fases epidemiológicas de doença e saúde. No mais, problemáticas socioeconômicas (a grande inflação) que reflete e vem refletindo, predominantemente, os negros, pobres e pessoas em situação de rua (Schwarcz et al., 2020; Goulart, 2005).

$\mathrm{Na}$ epidemia da gripe espanhola as pessoas também tinham que permanecer em suas casas por tempo indeterminado, evitar contatos com amigos parentes e a comunidade, evitar as famosas aglomerações, assim a transmissão ao longo do planeta ocorreu desde grandes navios do passado e hoje em dia se disseminam a partir dos aviões, que realizam viagens a partir de várias distâncias (Buss, 2007). Fatores este alinhados a ausência do governo em que não ofereceram as devidas medidas de proteção e contenção para essa população (Affonso da Silva, 2021; Villela, 2021).

O saneamento básico de má qualidade também é algo que pode e deve ser lembrado, visto que após tanto tempo dessas doenças, conseguimos fazer comparações de problemas que propiciaram pandemias antigas e na covid-19 (Villela, 2021; Reichert et al., 2022). Diferenças também podem ser vistas, como a maior parte das mortes na pandemia da gripe espanhola, ocorreu em sua maior parte em jovens, enquanto a covid-19 teve seu maior número no idosos (Goulart, 2005, Schwarcz et al., 2020; Kind \& Cordeiro, 2020; Gomes et al., 2012).

Percebe-se que as situações ocorridas em detrimento da Covid-19, foram vivenciadas nos anos anteriores durante outras crises de saúde pública provocadas por pandemias, revelando dificuldades e problemas em como um país com a sua política econômica pode demonstrar sua segurança sanitária a uma população. Dessa forma, o presente trabalho busca comparar, por meio da análise crítica e interpretativa, o passado da crise epidêmica da gripe espanhola e o presente da crise pandêmica da Covid-19 no Brasil. Evidenciando, dessa forma, as semelhanças atreladas ao sistema de saúde pública, tratando os aspectos sociais, políticos e econômicos (Goulart, 2005).

\section{Metodologia}

Para alcançar a finalidade desta pesquisa, o trabalho tem natureza de investigação bibliográfica, aplicando o método científico dialético. Busca-se entender o fenômeno por meio de uma revisão integrativa da literatura, examinando-se a nova pandemia da covid-19 e sua correlação histórica com a pandemia da gripe espanhola, de uma forma exploratória, crítica, explicativa e descritiva. Fazendo, para tanto, uma transição por diversas áreas do conhecimento como a geografia, a sociologia, pelos discursos midiáticos, a epidemiologia e a biomedicina (Prodanov et al., 2013).

Os dados foram coletados nas bases acadêmicas do Google Scholar, PubMed e Lilacs, assim como, também, foram utilizados jornais, revistas e outros tipos de informações por meios de comunicação de grandes sites nacionais como a British Broadcasting Corporation (BBC). Isto é, os recursos midiáticos anteriormente citados. Por critério de conveniência, designouse a preferência apenas por trabalhos que estivessem escrito em língua portuguesa e/ou inglesa. Destacamos que devido o objetivo desta pesquisa, não houve necessidade preliminar de submissão para um comitê de ética, sendo assim dispensável (Prodanov et al., 2013). A Figura 1 mostra o desenho metodológico deste estudo. 
Figura 1 - Desenho metodológico adotado na pesquisa bibliográfica.

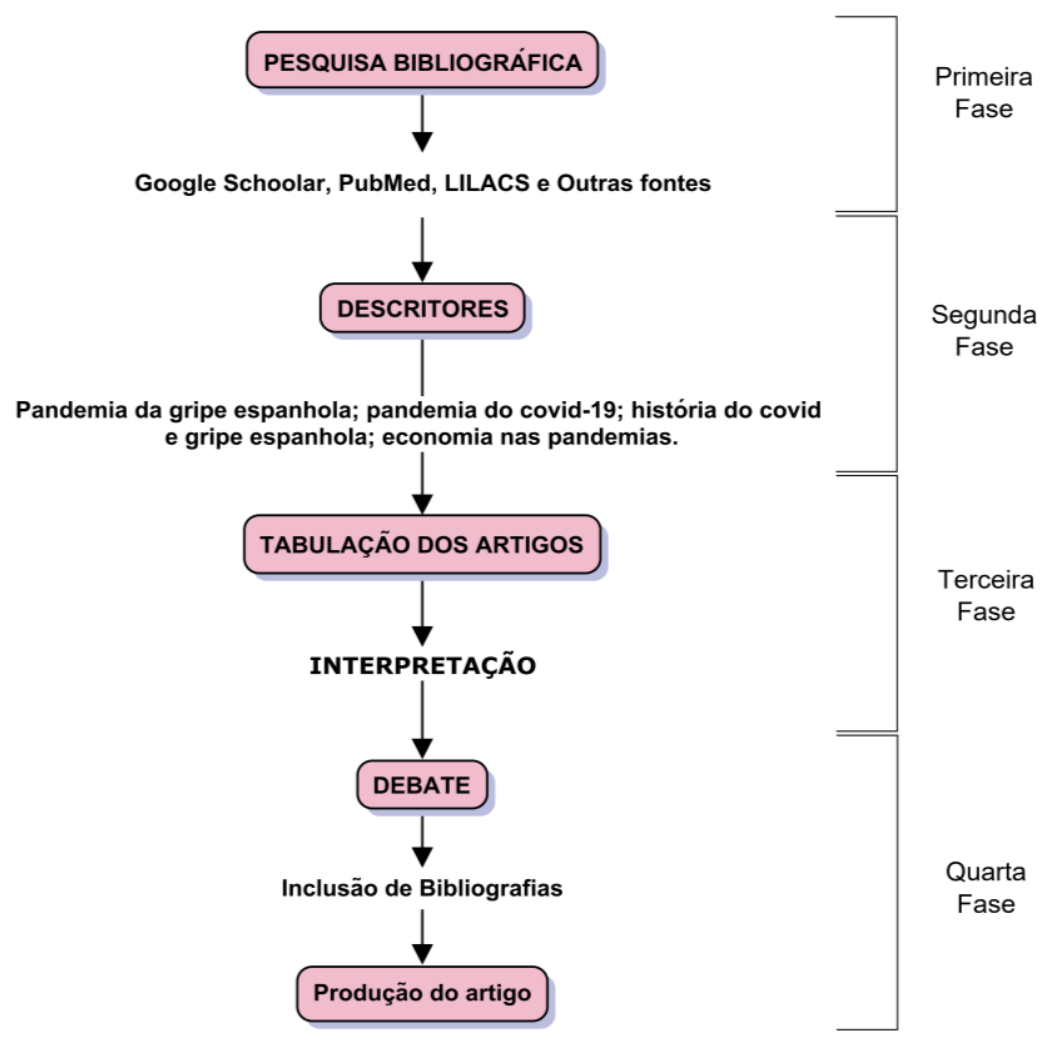

Fonte: Dados da Pesquisa.

Como mostrado no desenho da pesquisa durante a primeira fase do trabalho foi decido os meios de produção do artigo, caracterizando-se por uma pesquisa bibliográfica nas bases de banco de dados Google Schoolar, PubMed, LILACs e outras fontes como jornais e fotografias. Na segunda fase da pesquisa foi realizada a busca ativa nestes bancos de dados pelos descritores "pandemia da gripe espanhola", "pandemia do covid-19", "história da covid e gripe espanhola" e "economia nas pandemias", que delimitaram a linha cronológica do tema abordado, que como resultado obtiveram um total de 63 trabalhos e bibliografias ou documentos.

Logo após, na terceira fase, todos esses artigos foram lidos e interpretados, rastreando-se a informação contida em cada um dos trabalhos estava relacionada ao tema e objetivo proposto dentro dessa pesquisa, ocorrendo assim em conjunto com a quarta fase, aonde se debateu entre os autores desta pesquisa sobre a inclusão das bibliografias que possuíssem argumentação discursiva em relação ao tema objetivado por este trabalho, com opiniões, críticas e ideias para a saúde pública dentro da covid-19 e a pandemia da gripe espanhola. Desta forma, o total final de bibliografia quantificado foi de 55 trabalhos.

\section{Resultados e Discussão}

As comparações aqui utilizadas datam principalmente do trabalho de Heloisa Murgel Starling e Lilia Schwarcz (2020) intitulado 'A Bailarina da Morte: A gripe espanhola no Brasil', Livro escrito durante a pandemia da covid-19 que traz diversas reflexões sobre nossa sociedade, sobre a economia, a política, os aspectos históricos comparativos em que há ainda uma gama de informação epidemiológica. Apresentou-se com um dos principais achados em nossa pesquisa bibliográfica, fazendo-nos entender o quão importante se tornou a pesquisa científica não apenas pela descoberta da doença e de seus princípios biológicos, mas entender a problemática social, política e econômica, presente nas sociedades. Dessa forma, tratamos o livro 
como uma conversação durante o texto com suas reflexões para com a pandemia da gripe espanhola (Sousa, 2020; Dantas, 2013; Paulilo, 1999).

A disseminação da covid-19 é similar à da gripe espanhola, que ocorreu há mais de 100 anos, em um período final da Primeira Guerra Mundial, período de muito caos para diversos países, essencialmente para quem estava na linha de frente, os soldados. Outros países estavam ajudando com os mantimentos, poder bélico e alguns médicos, os chamados aliados, como os Estados Unidos da América (EUA), país este que dentro do contexto da gripe espanhola foi quem disseminou e levou para o outro lado do atlântico uma doença silenciosa e mortal que se alastrou pelos campos de guerra, matou diversos soldados e começou a avançar pelas cidades atacando os civis (Barry, 2005; Araripe, 2011; Trindadeet al., 2021).

A chegada da doença nos continentes não demorou, por meio de grandes navios foi propagada, podendo citar o Demerara, onde passou por diversas capitais, levando numerosas pessoas contaminadas com a doença, ele foi conhecido também como o "navio da morte", pois por cada capital que ele atracou foi acompanhado, a nova influenza (Barry, 2005; Schwarcz et al., 2020).

Assim como a covid-19, as origens da gripe espanhola são incertas, a teoria mais aceita aponta que ela teve seus primeiros casos no Estado do Kansas nos EUA, na base de Fort Riley do quartel Camp Fuston, no qual foi visto pelos médicos uma grande semelhança com a influenza. Entretanto, apresentou um quadro muito mais grave, havendo grande sangramento por todos os orifícios do corpo, identificando-se como mais uma nova cepa do H1N1, considerada mais mortal. Nesse sentido, há uma afinidade comum na Covid-19, já que também veio de uma similaridade genética com diversas transformações genômicas e junções de outros coronavírus, mas dessa vez de acordo com as teorias possuiria uma proteína (espicula ou spike do inglês) que o tornaria mais violento na hora de sua infecção nas células do organismo (Barry, 2005; Schwarcz et al., 2020; Gruber, 2020; Boni et al., 2020).

A partir da explicação da patologia no organismo, pode-se identificar o caminho que ela começou a percorrer no mundo, indagando como ela traçou diversas civilizações e matou milhões de civis em um curto período de tempo. Estamos falando da covid-19 ou da gripe espanhola? Certamente, estamos falando sobre as duas doenças, as duas parecem entrelaçadas e interligadas primeiramente pelo negacionismo. O negacionismo foi um dos principais pontos que fez com que em 1918 diversos soldados morressem nas trincheiras da guerra, muitos na linha de frente não sabiam da existência e as próprias autoridades se negaram a falar sobre, devido a guerra que ainda estava acontecendo na região, podendo gerar fracasso na batalha. Mal sabiam que todos os países estavam fracassando (Barry, 2005; Schwarcz et al., 2020; Vaz, Sanchotene et al., 2021; Bertuci, 2009).

Na pandemia da gripe espanhola no Brasil, o negacionismo foi visto também em virtude da relação de poder das grandes autoridades que não queriam estagnar a economia, optando por salvá-la em detrimento à população. Exemplo disso, foi o que o ocorreu em Salvador com o então presidente do Estado, Antônio Ferrão Moniz de Aragão que reforçou uma conspiração, na qual queria destruir o seu mandato enquanto a doença se espalhava, sendo essa uma invenção feita pelos opositores. Houve também o comentário do inspetor sanitário Jaime Silva no Rio de Janeiro, falando que não acreditava em micróbios, mas como é possível ver na Figura 2, também existiu uma grande negação também dos cidadãos brasileiros sobre as doença Covid-19, onde se perguntou se as pessoas realmente estavam morrendo dela ou se eram outras doenças, além de existir um grande desrespeito pelo luto corpo e vítima da doença que esteva presente em um vídeo na plataforma do Google chamada Youtube (Schwarcz et al., 2020; Souza, 2005; Souza, 2009; Brito et al., 2020).

Isso remete ao então presidente do Brasil, desde 2018, Jair Messias Bolsonaro com frases de negação no início da pandemia da covid-19 para a população como: "vamos todos morrer um dia", "e daí?" ou "gripezinha", é um exemplo de como a vida se tornou banal, trazendo reflexos de uma pessoa apática no meio de tantas mortes e destruição, administrando um país com milhões de pessoas. O fato é que não só a disseminação em massa do vírus aconteceu, como também a grande 
disseminação de notícias falsas foi vista, tornando-se um verdadeiro reflexo no cotidiano da população, sendo uma das consequências desse fato, a superlotação nos hospitais. Como é possível ver na Figura 3 e na Figura 4, ambas exibem que tanto na pandemia da covid-19 quanto na gripe espanhola houve uma grande falta de leitos para atender toda a população devido a superlotação, mostrando a dificuldade de um sistema de saúde fragilizado e extremamente sobrecarregado (Ribeiro et al., 2020; Silva, 2020; Teixeira et al., 2020; Szwako, 2020; Caponi, 2020; Krenak, 2020).

Figura 3 - Falta de Leitos no Estado do Rio de Janeiro na Pandemia da Gripe Espanhola.

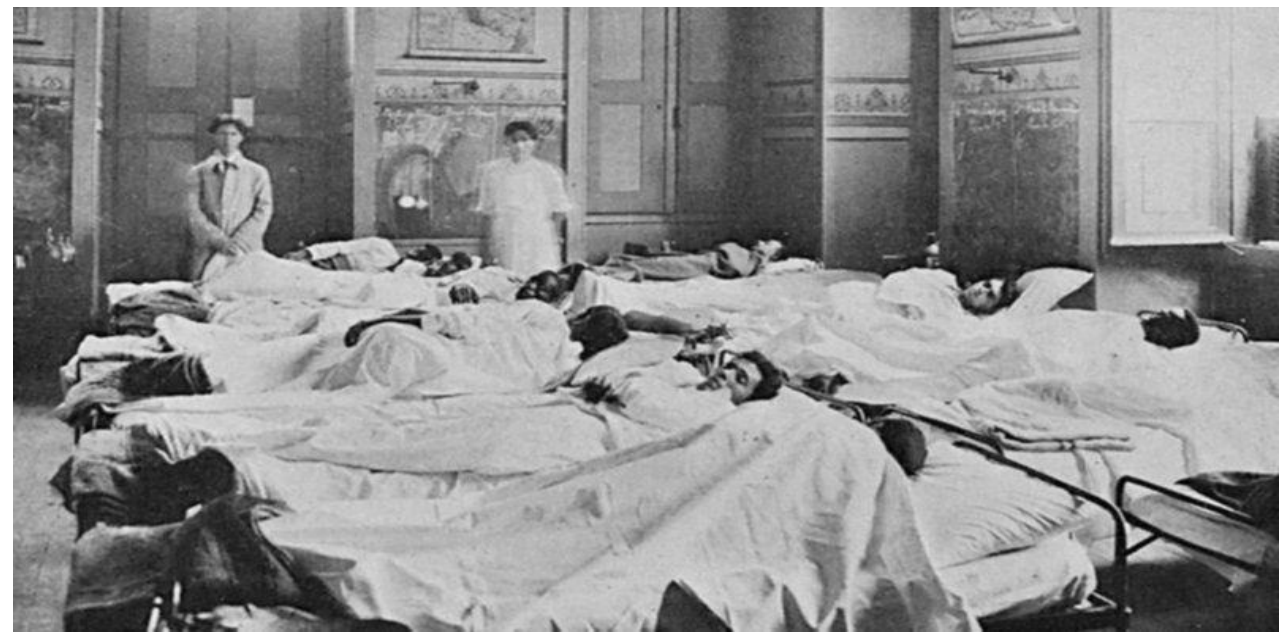

Fonte: Biblioteca Nacional (2021).

As semelhanças entre as duas pandemias são reais e facilmente perceptíveis. Elas demonstram laços de pessoas que estão acamadas e interligadas aos fatores primordiais da saúde, os "cuidadores", aqueles que cuidam da vida e juram pela proteção da saúde, estes que durante a pandemia demostraram tamanho esforço pelo zelo da saúde e que talvez sejam as últimas pessoas que alguns acamados ou, melhor dizendo, enfermos irão visualizar antes da sua morte (de Souza, 2021). O ponto central é que exatamente essas pessoas não deveriam estar em um leito de UTI e ver familiares ou amigos morrendo ao seu lado em um leito do hospital. São laços que quebram devido ao carecimento de uma saúde de qualidade. A saúde não é só um ato, ela também é conhecimento, o conhecimento impede que narrativas de padecimento ocorram ou, ao menos, sejam minimizados, todos merecem se despedir da melhor maneira possível e respeitosa, a história demonstra fragilidades e o presente comprova que fragilidades ainda estão exteriorizadas na saúde (Bermúdez et al., 2021; Noronha et al., 2020; Costa et al., 2020).

Figura 4 - Falta de leitos na pandemia da Covid-19 no Estado de Mato Grosso

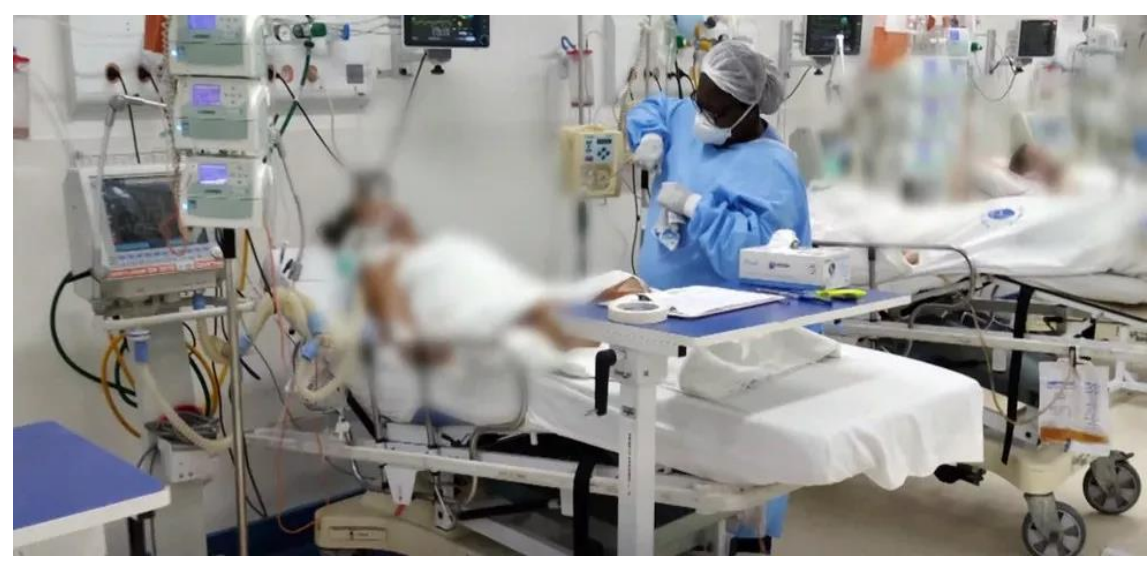

Fonte: Portal do G1 de Mato Grosso (2020) e Teixeira et al. (2020). 
O fato é que a negação da Covid-19 apenas trouxe vestígios do que ocorreu na pandemia da gripe espanhola, sendo que tal prática incentivou a proliferação da doença na população, somado a demora para implementação de medidas de contenção para que não existisse o que ocorreu no passado. O primeiro caso datado ocorreu no dia 26 de fevereiro de 2020 e apenas um dia após, já datavam 132 casos suspeitos. Este fato pode ser associado à gripe espanhola, na qual começou com 1 caso em uma base do exército e logo esse local inteiro de militares já estava apresentando os sintomas de suspeita se serem portadores da nova influenza (Barry, 2005; OMS, 2022).

Dessa forma, houve uma demora para a implementação de medidas de contenção da doença no país. A primeira morte ocorreu no dia 12 de março de 2020, no dia 08 de março de 2021 temos 11.051 .665 milhões de casos confirmados de pessoas que pegaram a doença e 266.398 mil pessoas que morreram devido a doença, podendo observar no Gráfico 1 e no Gráfico $2 \mathrm{o}$ dinamismo da doença, em que é observado um grande efeito dominó que ocorreu no Brasil por conta da presença do desgoverno brasileiro (Barry, 2005; OMS, 2022; Morales da Silva \& Batista Melo, 2021; Cavalcante et al., 2020).

Gráfico 1 - Número de casos acumulados de Covid-19 por semana de notificação no Brasil, entre os meses de 27 de agosto de 2020 até 22 de agosto de 2021.

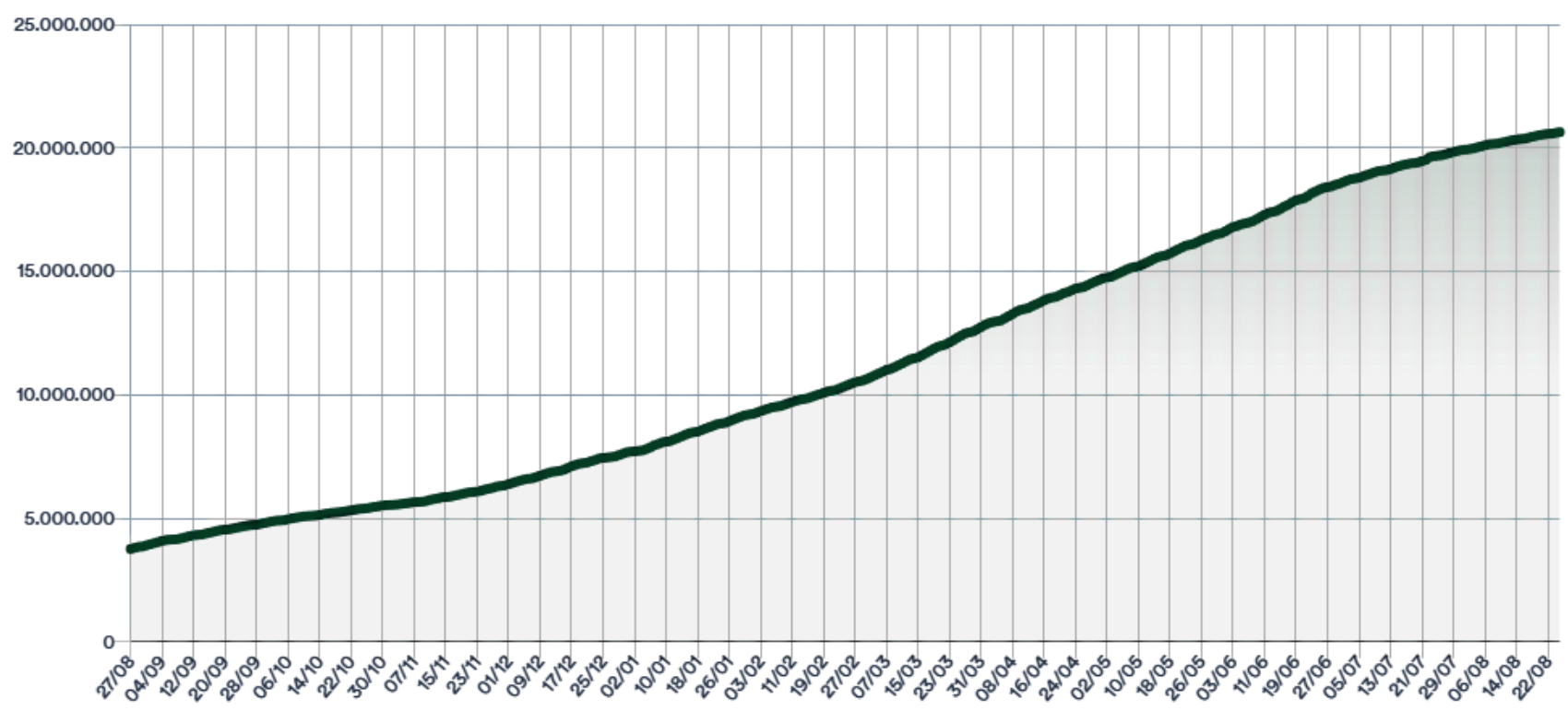

Fonte: Secretarias Estaduais de Saúde (adaptado de Ministério da saúde) (2022).

O crescimento progressivo do alastramento da doença foi alarmante. De modo exponencial, o covid-19 se expandiu rapidamente para diversas regiões do país (Antunes et al., 2020). Como é possível verificar no gráfico 1 e no Gráfico 2, a evolução dos casos acumulados tanto para confirmados quanto para óbitos em tão pouco tempo foi suficiente para ser comparado a outras pandemias, seja à que estamos estudando aqui - a gripe espanhola e a covid-19, ou a cólera e a peste bubônica, que se apresentam como pandemias que marcam momentos de grande crise e morte da população devido as precárias situações de saúde pública, como o saneamento básico, decorrentes da falta de administração governamental frente as crises de saúde (Cuero, 2020, Abreu, 2020). Só que agora estamos falando de contemporaneidade e de acordo com o Art. 6 da Constituição Federal do Brasil é direito universal de todo cidadão brasileiro o acesso a saúde de qualidade (1988), situação que não se mostrou verdadeiro durante a época de pandemia da covid-19 no Brasil, uma vez que essa garantia supriu de forma desigual os diversos setores sociais, especialmente no que se refere as populações mais vulneráveis, refletindo na propagação da doença e no aumento do número de casos e mortes causados por ela (Almeida et al., 2020; Farias, 2020). 
Gráfico 2 - Óbitos acumulados de covid-19 por data de notificação, 2020-2021, Brasil.

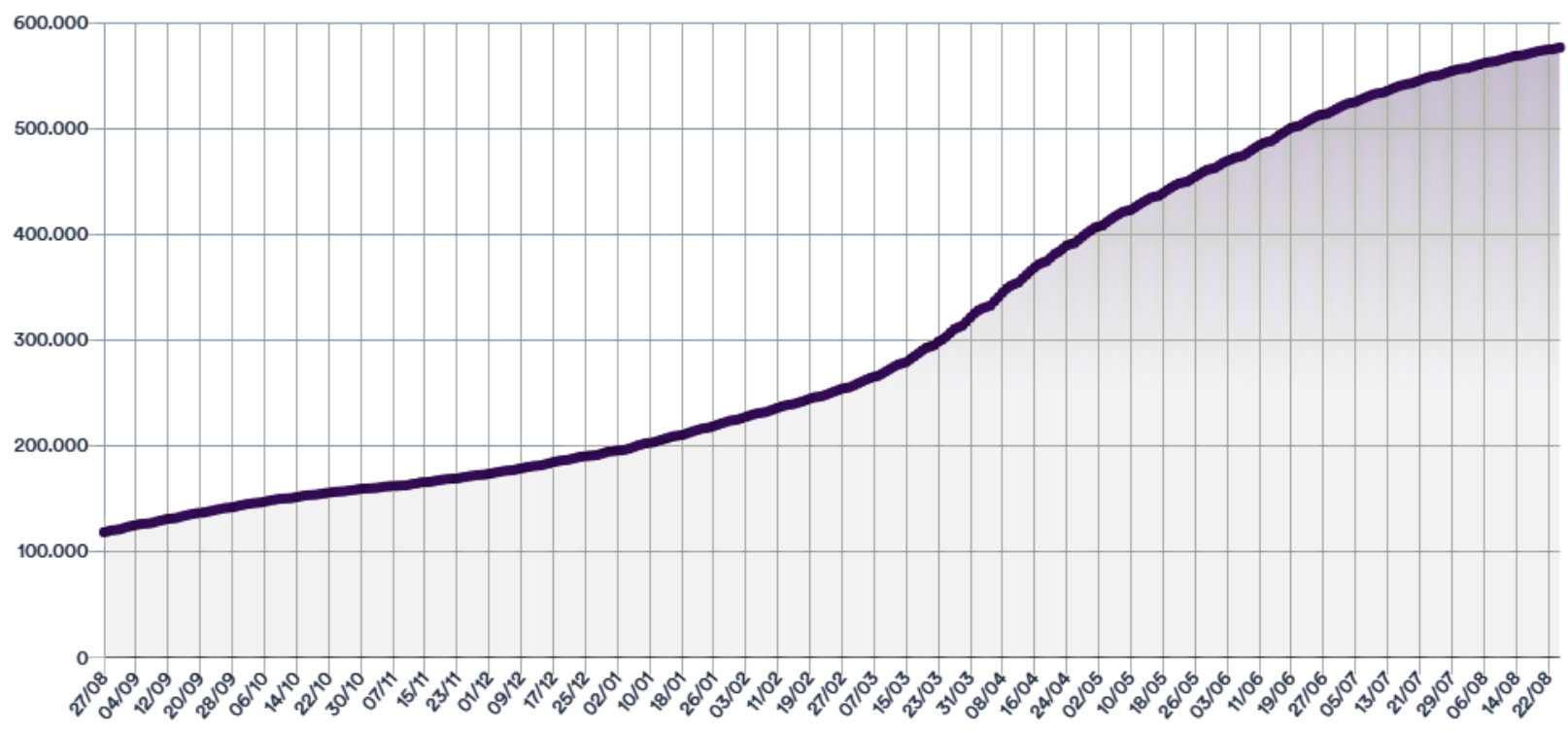

Fonte: Secretarias Estaduais de Saúde (adaptado de Ministério da Saúde) (2022).

Há quem diga que a doença matou menos que o normal, que os dados foram falsificados e que diagnosticaram de forma equivocada pessoas que nem sequer estavam com a covid-19. Diversas pesquisas mostraram que existiu uma grande subnotificação da doença no Brasil, que no caso o número de contaminados foi maior que os dados divulgados (Prado et al., 2020; Orellana et al., 2021; do Brasil API, 2020; de Oliveira et al., 2020; Caponi, 2020; Ribeiro et al., 2020);

Quando se correlaciona com a pandemia da gripe espanhola, observa-se que há uma variação nos dados de pessoas mortas acometidas pela doença com números que ficam entre 150 mil e 450 mil, sendo perceptível uma grande disparidade nos números publicados. Em uma pesquisa realizada no município de Breves, na região da linha do marajó, foi apontado que uma em cada quatro pessoas foi infectada pela doença, ou seja, cerca de pelo menos $25 \%$ da população já havia sido infectado com a doença, sendo um número diferente das estatísticas mostradas no período, já que nem 1\% teria se infectado de acordo com os testes confirmados. Portanto, pode-se configurar uma grande dificuldade no dimensionamento real do número de pessoas que sofreram com a doença na população, embora seja possível considerar que nós nunca chegaremos aos números reais de quantas pessoas foram realmente atingidas por tamanha doença (Souza et al., 2020, Epicovid19, 2020; Vieira et al., 2020; Bienath, 2020).

A pandemia, na realidade, tornou-se algo habitual e coletivo, visto que a maioria das pessoas já havia tido algum contato com o vírus e com as enfermidades da doença. Em decorrência, do alastramento da doença diante da população ser de maneira rápida e silenciosa, a busca por medidas de tratamentos da patologia foi maior, ocasionando a utilização irracional e algumas vezes sem embasamento científico evidente de plantas medicinais e de medicamentos, como a cloroquina, durante a pandemia da gripe espanhola e da Covid-19, decorrente da propagação de fake news legitimadas pelo Governo. O Presidente do Brasil, Jair Messias Bolsonaro e os grupos bolsonaristas, trataram com demasiada incompetência as informações produzidas e divulgadas pela Organização Mundial da Saúde (OMS), principalmente no que se refere a seriedade da pandemia e as medidas de contenção da doença, como a utilização de máscaras e de contribuições de ideologias políticas partidárias de extrema direita, agravando assim, a doença e aumentando o número de casos (Rodrigues et al., 2021; Miranda, 2021; Brito et al., 2020).

Nesse sentido, o uso de tais estratégias para o tratamento da Covid-19 ocorreram por conta da procura por um tratamento imediato, contudo houve a desvalorização no setor científico e consequentemente, o desinvestimento nele, sem 
haver recursos e estruturas disponíveis. Desse modo, isto nos remete à situação de um país em desenvolvimento, no qual não apresenta uma administração eficiente de recursos, além da negligência estatal perante determinadas doenças. Por consequência, a busca pela produção de uma vacina eficaz foi se prorrogando e a exigência do Estado pelas respostas rápidas e amplas no campo da saúde, tornaram-se complexos em ambas as pandemias (Mizuki Imoto, 2020; Miranda et al., 2020; Brito et al., 2020).

A debilidade no sistema de saúde é proporcionada devido a fatores como o crescimento acentuado no número de casos de indivíduos infectados que resulta em superlotação dos serviços de saúde e aumento na disseminação da doença, inclusive para os profissionais que auxiliam no tratamento das pessoas contaminadas. Em decorrência da crise do sistema de saúde atual, é notório a importância da vacinação para o combate a pandemia, visto que ela contribui para a redução na busca por assistência nos centros atendimento para a saúde e, como resultado contribui para evitar a superlotação deles, além de auxiliar na prevenção, redução de transmissão de contaminação e dos sintomas da doença (Fumagalli et al.,2020; Cardoso, 2020).

Embora existam diversos benefícios relativos à imunização, ela é capaz de acarretar questionamentos acerca da garantia e eficácia da vacina. O pensamento negativo da sociedade referente à vacinação decorre dos efeitos adversos que ela pode provocar, ínfimo acesso às informações sobre e ideais populares de que ela seria usada como controle governamental sobre a população, dando lugar a movimentos anti-vacinas de diversos setores da população. Em decorrência disso, a população desconfia, evita a administração vacinal e se desprotege, expondo-se ao contágio e, em função disso elevando o número de patologias (Nassarela et al., 2019; Beltrão et al., 2020).

Desta forma, os movimentos anti-vacinas começaram a ganhar forma e desenvolvimento por diversas sociedades nos vários extratos sociais, as primeiras formas que podemos citar são pela clássica conduta levada no século XX devido à gripe espanhola ou a revolta da vacina. Ela foi uma manifestação da população no início do século XX, em decorrência de uma legislação imposta na época, na qual seria uma vacina obrigatória contra a varíola para todos os cidadãos brasileiros. Esta decisão tomada pelo presidente da república levou a grandes proporções, desde uma crise política até mortes em massa da população (Sevcenko, 2010).

Com o objetivo de conter a disseminação da Covid-19 e impedir a sobrecarga dos sistemas de saúde, implementou-se medidas de controle e enfrentamento da doença, em contradições com os interesses políticos, por meio do distanciamento social, promovendo desde o fechamento de locais comerciais até a utilização de máscaras. No entanto, tais medidas ocorreram de forma tardia, ocasionando uma progressão dos casos da patologia nas redes de saúde, este fato é semelhante ao que ocorreu durante a pandemia da gripe espanhola em 1918. Além disso, durante as duas pandemias mencionadas, houve a negligência governamental diante dos setores baixos da sociedade e, por isso os mais pobres, os que possuíam uma situação econômica precária e de péssimas condições de vida, tornaram-se mais suscetíveis a adquirir a doença e disseminá-las, devido a exposição contínua, já que essas pessoas precisam do seu trabalho no dia a dia para sobreviver (Aquino et al, 2020; Schwarcz \& Starling, 2020).

O paralelo referente à ciência, saúde e política ocorreu diante das duas pandemias citadas, dando ênfase na pandemia da Covid-19. Durante esse período, ocorreu a produção de uma depressão econômica no país, na qual houve o aumento dos preços em diversos produtos utilizados pela população, principalmente no que diz respeito aos materiais de higiene, como o álcool em gel, aumento do desemprego e, portanto, queda na renda familiar, devido também às reduções salariais e de postos de trabalho. Em decorrência disso, o governo adotou medidas, como a criação do Auxílio Emergencial, para reduzir as consequências econômicas oriundo da pandemia da Covid-19 aos trabalhadores afetados no período da crise e, como efeito, evitar o aumento das desigualdades sociais e econômicas (Farias, 2020; Cardoso, 2020; Bresser-Pereira, 2020; Bridi, 2020).

Entretanto, esta medida apresentou dificuldades, dentre as quais há o atraso na execução e distribuição dos recursos, a 
falta de uma análise, realizada pelo Governo, referente aos preços existentes na época da distribuição dos recursos no momento da crise, acarretando na disposição de um benefício financeiro que não encobriu os possíveis gastos. Além disso, houve entraves burocráticos para os indivíduos que poderiam se beneficiar do programa, prejudicando na sustentação e manutenção da renda familiar, em contraposição ao objetivo principal do programa (Cardoso, 2020; Bresser-Pereira, 2020; Trovão, 2020).

\section{Considerações Finais}

Os problemas atuais e antigos em relação às duas doenças e como estas afetam a vida da sociedade quando observadas de uma concepção antropológica, trazem consigo diversos conceitos históricos, sociais, econômicos e políticos. As doenças podem trazer as pandemias que marcam uma ou mais gerações, firma um ponto no mapa, ou na linha histórica do tempo, que deve ser relembrado e discutido, mas ao que parece a pandemia da gripe espanhola tão pouco foi discutida no nosso país e, portanto, a ideia de aprender com o passado para que não aconteça novamente no futuro aparenta não funcionar. Como dito por John Ashton (2020), existe um grande clichê sobre as pandemias servirem de aprendizado, no caso se você não aprende essas lições da história, o seu destino é cometer esses mesmos erros, mas no final das contas sabemos que isso depende de diversos fatores como a educação, as políticas públicas adequadas e a promoção de saúde pertinente e apropriada.

Logo é válido lembrar que vivemos em um país em que a educação básica é precária, cabendo o questionamento sobre se as pessoas estudaram o que foi a gripe espanhola nas escolas e instituições de ensino do país. Por vezes o debate não é levantado, pois não existe conhecimento sobre o que se está se expondo para discussão. Torna-se complicado reivindicar e possibilitar aprender com o passado quando ele é tão pouco estudado pela população, principalmente no ensino público, em que está situado a maior parcela da nossa população.

O negacionismo afeta os grupos de riscos como os pobres e as pessoas em situação de rua que possuem pouco acesso à informação, sendo que as políticas públicas precárias e mal planejadas realizadas por um desgoverno total, são coisas que já foram vistas e se observam novamente. A doença se alastrou por todos os campos, atravessou fronteiras, afetou os indígenas e quilombolas, ocasionando dificuldades e mortes dessas populações que são sujeitas as injustiças e desigualdades sociais, necessitando assim de políticas inclusivas e de proteção, e não de conflitos e restrições. Como dito por Carlos Seidl (1913) e traduzido por Adriana Goulart (2005), as doenças se mostram como um fenômeno social que visa validar e autenticar o sistema público, isto é, entender se esse sistema vai suportar ajudar todas as classes sociais, todos os tipos de pessoas e se irá oferecer um sistema adequado de proteção.

Tais consequências resultam de incapacidade política e da ausência de bom senso sobre a realidade, dando preferência para as repercussões econômicas em detrimento das medidas de contenção da doença. Toda essa população poderia ter sido salva, mas enquanto outros países estão voltando a sua vida "normal", estamos atingindo um pico de infectados e de mortos. Definir as pandemias como uma crise, é torná-la momentânea e passageira, sem levar em consideração as consequências a curto e longo prazo que ela poderá trazer. $\mathrm{O}$ fato é que estamos caminhando para uma terceira onda da doença ou quem sabe nunca saímos da primeira onda.

Do modo que a pandemia ainda não acabou, há diversas dúvidas em relação a carga devastadora da doença no país e quais populações estão sendo altamente atingidas. Nesse sentido, o artigo traça uma linha temporal entre dois tipos de vírus, que proporcionaram pandemias marcantes para a história do país, buscando auxiliar nas pesquisas futuras de aprofundamento da pandemia do covid-19 e levar informações relevantes de aspectos existentes em diversos momentos da saúde humana ao longo de perspectivas históricas, sociais e econômicas. 


\section{Referências}

Abreu, C. M. (2020). Em tempos Covid, memória(s) de pandemias e do médico-cultural Ricardo Jorge. Revista Fontes Documentais, 3, 616-622. https://aplicacoes.ifs.edu.br/periodicos/fontesdocumentais/article/view/706

Affonso da Silva, S. (2021). Pandemia de covid-19 no brasil: o acesso e a qualidade dos serviços de saúde como determinante social. Revista Contexto Geográfico, 6(11), 56-76. https://doi.org/10.28998/contegeo.v6i11.12811

Almeida, W. da S. de, et al. (2020). Mudanças nas condições socioeconômicas e de saúde dos brasileiros durante a pandemia de COVID-19. Revista Brasileira de Epidemiologia, 23, e200105. https://doi.org/10.1590/1980-549720200105

Andrade, B. L. A. de \& Rocha, D. G. (2015). Doenças negligenciadas e bioética: Diálogo de um velho problema com uma nova área do conhecimento. Revista Bioética, 23(1), 105-113. https://doi.org/10.1590/1983-80422015231051

Antunes, B. B. de P., et al. (2020). Progression of confirmed COVID-19 cases after the implementation of control measures. Revista Brasileira de Terapia Intensiva, 32(2). https://doi.org/10.5935/0103-507X.20200028

Aquino, E. M. L., et al. (2020). Medidas de distanciamento social no controle da pandemia de COVID-19: Potenciais impactos e desafios no Brasil. Ciência \& Saúde Coletiva, 25(suppl 1), 2423-2446. https://doi.org/10.1590/1413-81232020256.1.10502020

Araripe, L. de A. (2011). História das guerras. São Paulo: Contexto.

Arias, J. (2020). O coronavírus dos ricos e o coronavírus dos pobres. El País Brasil. https://brasil.elpais.com/opiniao/2020-04-21/o-coronavirus-dos-ricos-e-ocoronavirus-dos-pobres.html

Ashton, J. (2020). COVID-19 and the 'Spanish' flu. Journal of the Royal Society of Medicine, 113(5), 197-198. https://doi.org/10.1177/0141076820924241.

Barry, J. M. (2005). The great influenza: The epic story of the deadliest plague in history. Penguin Books.

Beltrão, R. P. L., et al. (2020). Perigo do movimento antivacina: Análise epidemio-literária do movimento antivacinação no Brasil. Revista Eletrônica Acervo Saúde, 12(6), e3088. https://doi.org/10.25248/reas.e3088.2020

Bermúdez, D. \& Pamela, X. (2021). Contextos, narrativas e pessoas, reflexões sociais em meio à pandemia da Covid-19. https://repositorio.unb.br/handle/10482/40727

Bertucci, L. M. (2009). Gripe A, uma nova “espanhola”? Revista Da Associação Médica Brasileira, 55(3), 230-231. https://doi.org/10.1590/S010442302009000300001

Biernath, A. (2020). Mortes por covid-19 no Brasil estão 50\% acima do que apontam dados oficiais, calculam especialistas. BBC News Brasil. https://www.bbc.com/portuguese/brasil-55481551.

Boni, M. F., et al. (2020). Evolutionary origins of the SARS-CoV-2 sarbecovirus lineage responsible for the COVID-19 pandemic. Nature Microbiology, 5(11), 1408-1417. https://doi.org/10.1038/s41564-020-0771-4

BRASIL. (2022). Coronavírus Brasil. Recuperado 25 de janeiro de 2022, de https://covid.saude.gov.br/.

Bresser-Pereira, L. C. (2020). Financiamento da Covid-19, inflação e restrição fiscal. Brazilian Journal of Political Economy, 40(4), 604-621. https://doi.org/10.1590/0101-31572020-3193

Bridi, M. A. (2020). A pandemia Covid-19: Crise e deterioração do mercado de trabalho no Brasil. Estudos Avançados, 34(100), 141-165. https://doi.org/10.1590/s0103-4014.2020.34100.010.

Brito, J. C. M., et al. (2020). Uso irracional de medicamentos e plantas medicinais contra a COVID-19 (SARS-CoV-2): Um problema emergente. Brazilian Journal of Health and Pharmacy, 2(3), 37-53. https://doi.org/10.29327/226760.2.3-5

Buss, P. M. (2007). Globalização, pobreza e saúde. Ciência \& Saúde Coletiva, 12(6), 1575-1589. https://doi.org/10.1590/S1413-81232007000600019.

Campello, T., Falcão, T. \& Costa, P. V. da. (2014). O Brasil sem miséria (1a edição). Ministério do Desenvolvimento Social e Combate à Fome.

Caponi, S. (2020). Covid-19 no Brasil: Entre o negacionismo e a razão neoliberal. Estudos Avançados, 34(99), 209-224. https://doi.org/10.1590/s01034014.2020.3499.013

Cardoso, B. B. (2020). A implementação do Auxílio Emergencial como medida excepcional de proteção social. Revista de Administração Pública, 54(4), 1052-1063. https://doi.org/10.1590/0034-761220200267

Cardoso, P. V., Seabra, V. D. S., Bastos, I. B. \& Porto Costa, E. D. C. (2020). A importância da análise espacial para tomada de decisão: Um olhar sobre a pandemia de covid-19. Revista Tamoios, 16(1). https://doi.org/10.12957/tamoios.2020.50440

Cavalcante, J. R., et al. (2020). COVID-19 no Brasil: Evolução da epidemia até a semana epidemiológica 20 de 2020. Epidemiologia e Serviços de Saúde, 29(4). https://doi.org/10.5123/S1679-49742020000400010

Com UTIs lotadas, 65 pessoas com Covid-19 aguardam leitos em Cuiabá nesta quinta-feira. (2020). G1. Recuperado 25 de janeiro de 2022, de https://g1.globo.com/mt/mato-grosso/noticia/2020/07/02/com-utis-lotadas-65-pessoas-com-covid-19-aguardam-leitos-em-cuiaba-nesta-quinta-feira.ghtml

Costa, D. C. A. R., Bahia, L., Carvalho, E. M. C. L. de, Cardoso, A. M. \& Souza, P. M. S. (2020). Oferta pública e privada de leitos e acesso aos cuidados à saúde na pandemia de Covid-19 no Brasil. Saúde em Debate, 44(spe4), 232-247. https://doi.org/10.1590/0103-11042020e415 
COVID-19 no Brasil: várias epidemias num só país Primeira fase do EPICOVID19 reforça preocupação com a região Norte. (2020). http://epidemioufpel.org.br/uploads/downloads/276e0cffc2783c68f57b70920fd2acfb.pdf

Cuero, C. (2020). La pandemia del covid-19 [the covid-19 pandemic]. Revista Médica de Panamá - ISSN 2412-642X, 40(1). https://doi.org/10.37980/im.journal.rmdp.2020872

Dantas, E.B. (2013). A importância da pesquisa para a tomada de decisões. Brasília: UnB.

Oliveira, T. M. \& Araújo, A. C. O. (2020). Consequências da subnotificação dos casos de COVID-19 para a saúde pública no Brasil. InterAmerican Journal of Medicine and Health, 3. https://doi.org/10.31005/iajmh.v3i0.150

Souza, E. (2021). “O que será o amanhã?" Narrativas, pandemia e interfaces vida-morte. ESPACIOS EN BLANCO. Revista De Educación (Serie Indagaciones), 2(31), 351-364. https://doi.org/https://doi.org/10.37177/UNICEN/EB31-307.

Brasil API. (2020). O crescimento do Covid-19, e a subnotificação de casos de óbitos na população indígena no Brasil.

Farias, H. S. de. (2020). O avanço da Covid-19 e o isolamento social como estratégia para redução da vulnerabilidade. Espaço e Economia, 17. https://doi.org/10.4000/espacoeconomia.11357

Fumagalli, I. H. T., Sudré, G. A. \& Matumoto, S. (2020). Vacinação contra influenza no enfrentamento da pandemia de COVID-19: Relato de uma experiência e reflexões. Revista de Enfermagem do Centro-Oeste Mineiro, 10. https://doi.org/10.19175/recom.v10i0.3790

Garcia, L.P. \& da Silva, G.D.M. (2016). Doenças transmissíveis e situação socioeconômica no brasil: análise espacial. Brasília; Instituto de Pesquisa Econômica Aplicada.

Gomes, I. M. de A. M. \& Ferraz, L. M. R. (2012). Ameaça e controle da gripe A(H1n1): Uma análise discursiva de Veja, IstoÉ e Época. Saúde e Sociedade, 21(2), 302-313. https://doi.org/10.1590/S0104-12902012000200005

Goulart, A. da C. (2005). Revisitando a espanhola: A gripe pandêmica de 1918 no Rio de Janeiro. História, Ciências, Saúde-Manguinhos, 12(1), 101-142. https://doi.org/10.1590/S0104-59702005000100006

Gruber A. (2020). Covid-19: O que se sabe sobre a origem da doença. Jornal da USP. https://jornal.usp.br/artigos/covid2-o-que-se-sabe-sobre-a-origem-dadoenca/.

Hochman, G. (1993). Regulando os efeitos da interdependência: sobre as relações entre saúde pública e construção do Estado (Brasil 1910-1930). Revista estudos históricos. 6(11), 40-61.

Junior, A. \& Castro, J. M. de. (2018). O vírus e a cidade: Rastros da gripe espanhola no cotidiano da cidade de Belém (1918). 1 CD-ROM. http://repositorio.ufpa.br:8080/jspui/handle/2011/10118

Kind, L. \& Cordeiro, R. (2020). Narrativas sobre a morte: A gripe espanhola e a covid-19 no brasil. Psicologia \& Sociedade, 32 , e020004. https://doi.org/10.1590/1807-0310/2020v32240740

Krenak, A. (2020). O amanhã não está à venda. 1a edição. Companhia das Letras.

Miranda, B. C. (2021). A conspiração como pilar político das novas direitas: reflexões sobre o bolsolavismo. Revista de História da UEG, 10(02), e022102$\mathrm{e} 022102$.

Miranda, F. M. D., Santana, L. D. L., Pizzolato, A. C. \& Sarquis, L. M. M. (2020). Condições de trabalho e o impacto na saúde dos profissionais de enfermagem frente a covid-19. Cogitare Enfermagem, 25. https://doi.org/10.5380/ce.v25i0.72702

Mizusaki Imoto, A., et al. (2020). Cloroquina e Hidroxicloroquina no tratamento da COVID-19: Sumário de Evidências. Comunicação Em Ciências Da Saúde, 31(Supp11), 17-30. https://doi.org/10.51723/ccs.v31iSuppl 1.653

Morales da Silva, M. \& Batista Melo, L. (2021). Da "gripezinha” à pandemia: tensionamentos discursivos em torno da COVID-191. Cuadernos Del Centro De Estudios De Diseño Y Comunicación, (136). https://doi.org/10.18682/cdc.vi136.5040

Nassaralla, A. P. A., et al. (2019). Dimensões e consequências do movimento antivacina na realidade brasileira. A Revista Educação em Saúde.

Nogueira, J. V. D. (2020). Conhecendo a origem do sars-cov-2 (COVID 19). Revista Saúde e Meio Ambiente, 11(2), 115-124.

Noronha, K. V. M. de S., et al. (2020). Pandemia por COVID-19 no Brasil: Análise da demanda e da oferta de leitos hospitalares e equipamentos de ventilação assistida segundo diferentes cenários. Cadernos de Saúde Pública, 36(6), e00115320. https://doi.org/10.1590/0102-311x00115320

OMS. (2022). Coronavirus disease (COVID-19) - world health organization. Recuperado 25 de janeiro de 2022, de https://www.who.int/emergencies/diseases/novel-coronavirus-2019.

Orellana, J. D. Y., et al. (2021). Excesso de mortes durante a pandemia de COVID-19: Subnotificação e desigualdades regionais no Brasil. Cadernos de Saúde Pública, 37(1), e00259120. https://doi.org/10.1590/0102-311x00259120

Paulilo, M.A.S. (1999). A pesquisa qualitativa e a história de vida. Serviço social em revista.

Prado, M. F. do, et al. (2020). Analysis of COVID-19 under-reporting in Brazil. Revista Brasileira de Terapia Intensiva, 32(2). https://doi.org/10.5935/0103507X.20200030. 
Prodanov, C.C. \& de Freitas, E.C. (2013). Metodologia do trabalho científico: métodos e técnicas da pesquisa e do trabalho acadêmico-2 ${ }^{\mathrm{a}}$ Edição. Editora Feevale.

Reichert, A. P. da S., et al. (2022). Repercussões da pandemia da Covid-19 no cuidado de lactentes nascidos prematuros. Escola Anna Nery, 26(spe), e20210179. https://doi.org/10.1590/2177-9465-ean-2021-0179

Ribeiro, L. \& Bernardes, A.T. (2020). Cedeplar: Centro de Desenvolvimento e Planejamento Regional de Minas Gerais - UFMG - Nota Técnica: Atualização da Estimativa de Subnotificação em Casos de Hospitalização por Síndrome Respiratória Aguda e Confirmados por Infecção por Covid-19 no Brasil e Estimativa para Minas Gerais. https://www.cedeplar.ufmg.br/noticias/1244-nota-tecnica-atualizacao-da-estimativa-de-subnotificacao-em-casos-dehospitalizacao-por-sindrome-respiratoria-aguda-e-confirmados-por-infeccao-por-covid-19-no-brasil-e-estimativa-para-minas-gerais.

Rodrigues, F.C. \& Baronas, R. L. (2021). ENCICLOPÉDIA DISCURSIVA DA COVID-19: BALANÇO E PERSPECTIVAS. Cadernos da Pedagogia.

Santos, A. A. P. dos (org). (2021). Vulnerabilidades e seus impactos nos grupos humanos em tempos de covid-19. Editora da Universidade Federal de Alagoas. http://www.repositorio.ufal.br/jspui/handle/123456789/8035

Schwarcz, L. M. \& Starling, H. M. M. (2020). A bailarina da morte: A gripe espanhola no Brasil. Companhia Das Letras.

Segata, J. (2020). Covid-19, biossegurança e antropologia. Horizontes Antropológicos, 26(57), 275-313. https://doi.org/10.1590/s0104-71832020000200010

Seidl, C. (1913). A função governamental em matéria de higiene. Anais da Biblioteca Nacional. 35;175-90.

Sevcenko, N. (2010). A revolta da vacina: Mentes insanas em corpos rebeldes (Nova ed.). Cosac Naify.

Silva, A. M. (2020). (Não)É só uma gripezinha: Argumentação e realidade forjada nos pronunciamentos de jair bolsonaro sobre a covid-19. Revista Eletrônica de Estudos Integrados em Discurso e Argumentação. https://doi.org/10.47369/eidea-20-2-2736

Sousa, T. V. de, et al. (2020). COVID-19: A importância da pesquisa científica. Revista de Divulgação Científica Sena Aires, 573-575. https://doi.org/10.36239/revisa.v9.nEsp1.p573a575

Souza, C. M. C. de. (2005). A gripe espanhola em Salvador, 1918: Cidade de becos e cortiços. História, Ciências, Saúde-Manguinhos, 12(1), 71-99. https://doi.org/10.1590/S0104-59702005000100005

Souza, C. M. C. de. (2009). A gripe espanhola na Bahia: Saúde, política e medicina em tempos de epidemia. EDUFBA; Editora Fiocruz.

Souza, K. O. da, et al. (2020). Covid-19 e o cenário atual da Cidade de Castanhal -PA, Brasil. Research, Society and Development, 9(8), e421985717. https://doi.org/10.33448/rsd-v9i8.571

Szwako, Z. (2020). O que nega o negacionismo?. Cadernos de Subjetividade. 1(21): 71-78.

Teixeira, C. F. de S., et al. (2020). A saúde dos profissionais de saúde no enfrentamento da pandemia de Covid-19. Ciência \& Saúde Coletiva, 25(9), 34653474. https://doi.org/10.1590/1413-81232020259.19562020

Tesini B.L. (2021). Coronavírus e síndromes respiratórias agudas (Mers and sars)—Doenças infecciosas. ([s.d.]). Manuais MSD edição para profissionais. Recuperado 25 de janeiro de 2022, de https://www.msdmanuals.com/pt-br/profissional/doen\%C3\%A7as-infecciosas/v\%C3\%ADrusrespirat\%C3\%B3rios/coronav\%C3\%ADrus-e-s\%C3\%ADndromes-respirat\% $\mathrm{C} 3 \% \mathrm{~B} 3$ rias-agudas-covid-19-mers-e-sars

Trindade, E. L. \& Fortes, I. G. (2021). Gripe Espanhola e SARS-CoV-2: Cem anos de diferença que nos igualam. Revista Eletrônica Acervo Científico, 28, e7758. https://doi.org/10.25248/reac.e7758.2021

Trovão, C. J. B. M. (2020). A pandemia da covid-19 ea desigualdade de renda no Brasil: um olhar macrorregional para a proteção social e os auxílios emergenciais. Natal: Universidade Federal do Rio Grande do Norte.

Ujvari, S. C. (2009). A história da humanidade contada pelos vírus: bactérias, parasitas e outros microorganismos. Contexto.

Vaz, P., Sanchotene, N. \& Santos, A. (2021). Quanto dura uma catástrofe? Nação, indivíduo e trauma na Gripe Espanhola. Revista Brasileira de História da Mídia, 9(2). https://doi.org/10.26664/issn.2238-5126.92202011745

Vieira, I. C.G., Pereira, F., Ferraz, D. \& Ramos, C. (2020). NOTA TÉCNICA 01 Panorama da COVID-19 nos municípios do Marajó, Pará. Belém: Museu Paraense Emílio Goeldi.

Villela, E.F. de M. (2021). COVID-19, Saúde and Interdisciplinaridade O Impacto Social de Uma Crise de Saúde Pública Pode Gerar. Jundiaínbsp; Paco e Littera. http://public.eblib.com/choice/PublicFullRecord.aspx?p=6735941.-justificado). 